\title{
Yıkama İşleminin Bezayağı Kumaşların Sürtme Haslığına Etkileri
}

\author{
Yahya CAN $^{1 *}$, Muhammet AKAYDIN ${ }^{2}$
}

\author{
${ }^{1}$ Pamukkale Üniversitesi, Tekstil Teknolojisi Programı, Denizli, Türkiye
}

\begin{abstract}
ÖZET: Yıkama işlemi esnasında kullanılan kimyasallar maddeler ve mekanik hareketler sonucu tekstil mamulleri zarar görebilmektedir. Bu deneysel çalışmada; yıkama sıcaklığı, yıkama süresi ve yıkama tekrarı ile pamuklu bezayağı kumaşlarda yaş ve kuru sürtme haslığının değişimi incelenmiştir. Genel olarak kuru sürtme haslıkları yaş sürtme haslıklarından yüksektir. Sonuçlara göre yıkama süresi, yıkama sıcaklığı ve yıkama tekrarı artıkça kuru ve yaş sürtme haslıkları düşmektedir. Yıkama sıcaklığı ve yıkama süresinin arttığı durumlarda yaş sürtme haslığındaki düşüş kuru sürtme haslığındaki düşüşten daha fazladır. İlave olarak, yıkama tekrarının arttığı durumlarda ise kuru sürtme haslığındaki düşüşler yaş sürtme haslığındaki düşüşlere göre daha fazla olarak bulunmuştur. görülmüştür.
\end{abstract}

Anahtar Kelimeler: Sürtme Hası̆̆ğ, Bezayă̆ı Kumaş, Yıkama Süresi, Yıkama Sıcaklı̆̆ı, Yıkama Tekrarı.

\section{Effects of Laundering Process on Rubbing Fastness of Plain Fabric}

\begin{abstract}
Textile products are damaged by the chemical and mechanical distortions they are exposed to during laundering. In this experimental study, the effects of laundering duration, laundering temperature and repeated laundering on wet - dry rubbing fastness of cotton plain fabrics were investigated. In general the dry rubbing fastness is higher than wet rubbing fastness. According to results, the increase of laundering duration, temperature and the number of repetitive laundering decreased the wet - dry rubbing fastness. The decrease of wet rubbing fastness is higher than dry rubbing fastness in the situations of increased washing temperature and washing time. Additionally, the decrease of dry rubbing fastness is higher than wet rubbing fastness in the situations of increased repeated laundering.
\end{abstract}

Keywords: Rubbing Fastness, Plain Fabric, Laundering Duration, Laundering Temperature, Repeated Laundering.

\section{GíRiş}

Y1kama, tekstil materyalindeki kirlilikleri veya daha önceki boyama, basma gibi işlemlerde lif yüzeyinde tutunan fikse olmamış boyarmaddeleri ve yardımcı kimyasal maddeleri uzaklaştırmak için, gerektiğinde 1slatıc1, yıkama maddesi gibi yardımcı malzemelerle temizleme işlemidir (1).

Haslık bir tekstil ürününün gerek üretimi gerekse kullanım sırasında karşı karşıya kaldığı etkenlere dayanma gücüdür. Genel olarak hasliklar fabrikasyon haslıkları ve kullanım haslıkları olarak ikiye ayrılmaktadır (2). Kullanım haslıkları içinde en önemlilerinden birisi de sürtme haslığıdır. Çünkü tekstil mamulleri kullanımları sırasında diğer tekstil mamulleri ile sürekli sürtünme halindedir. Bu sürtünme kuvvetinin etkisiyle kumaşlar aşınabilir, boncuklanma görülebilir ve renginde açılma ve solmalar görülebilir.

Sürtme haslığı, boyalı veya baskılı tekstil mamullerinin beyaz kumaşla sürtünmesinde boyanın kumaşa geçme derecesi veya kumaşı kirletmeye karşı direnmesidir. Numuneler kuru (veya istenirse 1slak), boyasız, pamuklu refakat kumaşına karşı sürtülür.
Refakat kumaşının renk alma oranı, lekelenme gri skalasına göre tespit edilir.

Renkli bir kumaşın sürtme haslığı; boyamada kullanılan boyarmadde grubu, kumaş cinsi ve konstrüksiyonu, terbiye prosesleri, boyama yöntemi ve boyama sonrası uygulanan art işlemeler gibi parametrelere bağlı olarak değişmektedir (3). Çektirme yöntemiyle yapılan boyama işleminde genellikle emdirme yöntemiyle yapılan boyamalara göre renk haslık değerleri yüksektir.

Giysiler ve ev tekstil ürünleri belirli süre kullanıldıktan sonra kirlenirler ve tekrar kullanılabilmeleri için yıkanmak zorundadırlar. $\mathrm{Bu}$ sebeple giysi ve ev tekstil ürünlerinin faydalı ömürlerinin uzun olmasında yıkama işlemine dayanıklı olması da oldukça önemlidir. Yıkama işleminde işlem ve mamul kalitesine etki eden pek çok faktör vardır. Bunlar; yıkama sayısı tekrarı, kullanılan suyun özellikleri, kullanılan kimyasal maddelerin miktarı ve kalitesi, yıkama sıcaklığı ve süresi, kurutma sıcaklığı ve şeklidir. Yıkama işlemi genellikle sıcakta ve uzun sürede yapıldığından yıkama işlemiyle boyalı kumaşın sürtme haslığının düşmesi mümkündür. Özellikle yıkama sıcaklığı fiksaj sıcaklığını aşarsa bu düşme daha belirgin olacaktır. 
Yıkama işleminin dokuma ve örme kumaşların bazı mekanik özellikleri üzerindeki etkilerinin incelendiği çalışmalar bulunmaktadır (Demirhan ve Meriç 2004, Erdem İşmal 2008, Lau v.d.2002, Quaynor v.d. 2000, Sabina v.d. 2008). Araştırmacılar bu çalışmalarda genel olarak tekrarlı yıkama ve kurutma işleminin dokuma ve örme kumaşlarda bazı mekanik özellikler üzerinde olumsuz etkileri olduğunu ifade etmişlerdir.

Önal ve Candan 2003 yılında yaptıkları çalışmada; pamuk ve pamuk polyester karışımı örme kumaşların yıkama ve kurutma işlemleri sonrası çekme ve büzülme eğiliminde olduğunu belirtmişlerdir (8).

Yurdakul ve arkadaşları 2002 yılında yapmış oldukları bir çalışmada boyama işleminden sonra kullanılan yumuşatıcıların yaş sürtme haslığını etkilemediği kuru sürtme haslığını ise azalttığını ifade etmişlerdir. Ayrıca normal fiksatörlerin de yaş ve kuru sürtme haslığınını etkilemediğini belirtmişlerdir (9).

Koç ve Ayyıldız 2004 yılında yaptıkları çalışmada farklı konstrüksiyonlardaki denim kumaşların sürtme haslıklarını yaş ve kuru olarak ölçmüşlerdir. İnceledikleri tüm kumaşlar için yaş sürtme haslıklarının kuru sürtme haslıklarından daha düşük olduğunu belirtmişlerdir. Ayrıca doku yapısının hammaddenin ve atk1 ipliği üretim şeklinin sürtme haslığına etki etmediğini ifade etmişlerdir (10).

Balcı ve Oğulata 2006 yılında yaptıkları çalışmalarında poliester/viskon/elastan karışımlı dokuma kumaşlarda, kumaşın son rengini değiştirmeden, altı farklı indirgen yıkama maddesi ve bir adet reaktif yıkama maddesi kullanarak yapılan yıkama işlemleriyle yaş ve kuru sürtme haslık değerlerini arttığını ifade etmişlerdir (11).

İçoğlu 2006 yılında yaptığı çalışmasında; 3 farklı tonda ve 4 farklı yöntemle reaktif boyarmadde kullanarak boyanan dokuma kumaşlarda kuru sürtme haslıklarında farklılıklar görüldüğünü ancak yaş sürtme haslıklarında ise önemli bir farklılık görülmediğini belirtmiştir (12).

Demir ve Mutlu 2006 yılında yaptıkları çalışmada, süprem ve ribana kumaşlarda kırmızı ve lacivert renkler için yıkama sonrası yapılan art işlemlerin kuru sürtme haslığı üzerinde önemli bir etkisinin olmadığını belirtmişlerdir (13).

Tamtürk 2007 yılında yaptığı çalışmada 3 farklı konstrüksiyondaki \% 100 pamuklu kumaşlara merserizasyon haricinde diğer ön terbiye işlemlerini uygulamış ve daha sonra kumaşların yaş ve kuru sürtme haslıklarını ölçmüştür. Sonuç olarak uygulanan ön terbiye işlemlerinin kuru ve yaş sürtme haslığı üzerinde önemli bir etkiye sahip olmadığını belirtmiştir (14).

Çetinaslan ve arkadaşları 2013 yılında yaptıkları çalışmalarında, üç farklı gramajdaki denim kumaşlara uygulanan yıkama işlemiyle kumaşların kopma ve yırtılma mukavemetlerinin azaldığını belirtmişlerdir(15).

\section{MATERYAL VE METOT}

$\mathrm{Bu}$ çalışmanın amacı yıkama süresi, yıkama sıcaklığı ve yıkama tekrarının sürtme haslığı üzerine etkilerinin belirlenmesidir. Bu amaç için \% 100 pamuk karde iplikleri ile üretilen bezayağı kumaşlar kullanılmıştır. Çözgü ipliği numarası Ne 20 büküm katsayısı $\alpha_{\mathrm{e}}=4$, atkı ipliği numarası Ne 20 ve büküm katsayısı $\alpha_{\mathrm{e}}=3$ olarak seçilmiştir. Kumaş özelliklerinin ölçümlerinde ve yıkama işleminde kullanılan standartlar Çizelge 1'de verilmiştir. Laboratuvardaki sıcaklık değeri $20^{\circ} \mathrm{C}$ ve nispi nem ise $\% 65^{\prime}$ dir.

Çizelge 1. Kumaş özelliklerinin ölçümünde ve yıkama işleminde kullanılan standartlar

\begin{tabular}{|c|c|}
\hline Kumaş Özellikleri & Standart \\
\hline Atkı - çözgü sıklıkları & ASTM D 3775-03a \\
\hline Gramaj & ASTM D 3776-96 \\
\hline $\begin{array}{c}\text { Sürtünmeye karşı renk } \\
\text { haslığı }\end{array}$ & AATCC - 8 \\
\hline $\begin{array}{c}\text { Ev tipi çamaşır makinesi ile } \\
\text { yıkama ve kurutma işlemleri }\end{array}$ & TS 5720 EN ISO \\
\hline
\end{tabular}

Kumaşlar elektronik armürlü Toyoda Jat 600 dokuma makinesinde $23 \mathrm{tel} / \mathrm{cm}$ atkı siklığında ve 24 tel/cm çözgü sıklığında üretilmiştir. Üretilen kumaşlara işletme şartlarında haşıl sökme ve ağartma işlemleri uygulanmıştır. Kumaşlar $1 \mathrm{~g} / \mathrm{L}$ enzim, 2 g/L noniyonik 1slatıc1, $2 \mathrm{~g} / \mathrm{L}$ tuz ve $0,3 \mathrm{~g} / \mathrm{L} \mathrm{CaCl}_{2}$ içeren çözelti ile $70^{\circ} \mathrm{C}$ 'de 4 saat emdirilmiş ve daha sonra soğuk su ile durulanarak haşıl sökme işlemi yapılmıştır. Daha sonra $\% 5^{\prime}$ lik $\mathrm{NaOH}$ ile $95^{\circ} \mathrm{C}$ 'de padroll yöntemine göre 2 saat süre ile emdirilerek hidrofilleştirme işlemi tamamlanmıştır. Ağartmada $\mathrm{H}_{2} \mathrm{O}_{2}$ kullanılmıştır. Daha sonra kumaş işletme şartlarında reaktif boyarmadde ile pad batch yöntemiyle (soğuk bekletme) tek banyolu yöntemle emdirilerek lacivert renkte boyanmıștır. Boyarmadde olarak Remazol Red RB ${ }^{\circledR}$ kullanılmıştır. Boyarmadde ile birlikte flotteye üre, tuz, migrasyon önleyici, ıslatıcı ve alkali de ilave edilmiştir. Alkali olarak sodyum hidroksil kullanılmıştır. Flotte sıcaklığ 1 $25{ }^{\circ} \mathrm{C}$ dir. Daha sonra kumaş folye ile sarılarak ortam sıcaklığında 12 saat bekletilerek fiksaj işlemi tamamlanmıştır. Daha sonra kumaş önce soğuk su ile 
sonra $80{ }^{\circ} \mathrm{C}$ sıcak su ile son olarak da tekrar soğuk su ile yıkanmıştır. Son olarak da kumaş $150{ }^{\circ} \mathrm{C}$ 'de 45 dakikada baraban ile kurutulmuştur.

Daha sonra kumaşlar ev tipi çamaşır makinesinde 3 farklı sıcaklık ve 2 farklı sürede 6 farkl şekilde yıkanmıştır. Yıkama işleminde kullanılan ev tipi çamaşır makinesinde minimum yıkama sıcaklığ $20^{\circ} \mathrm{C}$ maksimum yıkama sicaklığ 1 ise $90^{\circ} \mathrm{C}$ 'dir. $\mathrm{Bu}$ sebeple yıkama sicaklıkları $20^{\circ} \mathrm{C}, \quad 60^{\circ} \mathrm{C}$ ve $90^{\circ} \mathrm{C}$ olarak seçilmiştir. Her bir y1kamadan sonra kumaşlar oda sıcaklığında sererek kurutulmuş ve daha sonra kumaşların sürtme haslıkları yaş ve kuru olmak üzere Crockmeter Sürtme Haslığı Test Cihazı ile ölçülmüştür.

Sürtme haslığ kumaşları kuru veya yaş halde sürtmeye tabi tutulduğunda rengin gösterdiği dayanıklılığı kontrol etmek amacıyla yapılan haslık testidir. Bu işlem yaş ve kuru kumaşlar için ayrı ayrı yapılmıștır. Kuru numune kumaş sabit bir şekilde alete yerleştirildikten sonra standart beyaz kumaşa $20 \mathrm{kez}$ sürtülmektedir. Standart beyaz kumaşların 1slatılması kumaşın kendi ağırlığ kadar saf su ile gerçekleştirilir. Standart beyaz kumaş üzerinde meydana gelen renk bulaşması ise 1'den 5'e kadar derecelendirilen gri skala ile değerlendirilmiştir.
Burada 1 numune kumaşın sürtme haslığının en düşük 5 ise en yüksek olduğunu göstermektedir. Bazı ara durumlarda 1-2 veya 4-5 vb. ara değerlendirmelerde yapilabilmektedir.

Yıkama işleminde piyasada sik olarak kullanılan bir deterjan kullanılmıștır. Söz konusu deterjan içerik olarak; \%5'den az noniyonik aktif madde, polikarboksilat, fosfonat, sabun, \%5-15 aniyonik aktif madde, oksijen bazlı ağartıcı, \%15-30 fosfat ve parfüm içermektedir. Ev tipi çamaşır makinesinde yıkama yapılmasının sebebi günlük hayatta karşılaşılan yıkama işlemine benzerlik sağlaması içindir. Yıkama tekrarının kumaş sürtme haslığı özelliği üzerindeki etkilerinin incelenebilmesi için ise 6 farklı yıkama işlemi 20'şer kere tekrarlanmış ve 20. yıkamanın sonunda kumaşın sürtmeye karşı renk haslığ 1 tekrar ölçülmüştür.

\section{BULGULAR}

Kumaşlara uygulanan yıkama işlemlerine ait bilgiler ve ilk yıkama işlemi ile 20. yıkama işlemi sonrası kuru ve yaş sürtme haslığı dereceleri Çizelge 2'de verilmiştir.

Çizelge 2. Kumaşlara uygulanan yıkama işlemleri ve yıkama işlemleri sonrası sürtme haslıkları

\begin{tabular}{|c|c|c|c|c|c|c|}
\hline \multirow{2}{*}{$\begin{array}{c}\text { Y1kama } \\
\text { No }\end{array}$} & \multirow{2}{*}{$\begin{array}{c}\text { Süre } \\
\text { (dakika) }\end{array}$} & \multirow{2}{*}{$\begin{array}{c}\text { Sicaklık } \\
\left({ }^{\circ} \mathrm{C}\right)\end{array}$} & \multicolumn{2}{|c|}{$\begin{array}{c}\text { İlk Yıkama Sonrası } \\
\text { Sürtme Haslığı }\end{array}$} & \multicolumn{2}{|c|}{$\begin{array}{l}\text { 20. Yıkama Sonrası } \\
\text { Sürtme Haslığı }\end{array}$} \\
\hline & & & Kuru & Yaş & Kuru & Yaş \\
\hline 1 & \multirow{3}{*}{30} & 20 & 4 & 4 & 4 & $3-4$ \\
\hline 2 & & 60 & 4 & $3-4$ & 3 & 3 \\
\hline 3 & & 90 & $3-4$ & 3 & 3 & 3 \\
\hline 4 & \multirow{3}{*}{60} & 20 & $3-4$ & 3 & 2 & $1-2$ \\
\hline 5 & & 60 & 3 & 2 & $1-2$ & 1 \\
\hline 6 & & 90 & 3 & $1-2$ & $1-2$ & 1 \\
\hline
\end{tabular}

\subsection{Yıkama Süresi ile Kumaş Sürtme Haslığının Değişimi}

30 ve 60 dakikada yapılan y1kamalar $20^{\circ} \mathrm{C}, 60^{\circ} \mathrm{C}$ ve $90^{\circ} \mathrm{C}$ sıcaklıklarda uygulanmıştır. 1 ve 4 numaral yıkamalar $20^{\circ} \mathrm{C}$ 'de, 2 ve 5 numaralı yıkamalar $60^{\circ} \mathrm{C}$ 'de ve 3 ve 6 numaralı yıkamalar ise $90^{\circ} \mathrm{C}$ 'de yapılmıştır. 3 farklı sıcaklıktaki yıkamalar için yıkama süresi ile sürtme haslığının arasındaki ilişkiler Şekil 1 ve Şekil 2'de görülmektedir. Grafik çizimini kolaylaştırmak ve grafikleri daha anlaşılabilir hale getirmek için grafik oluşumunda; gri skaladaki 1-2 değeri için 1,5, 2-3 değeri için 2,5 ve 3-4 değeri için ise 3,5 değeri kullanılmıştır. Çizelge 2'de verilen değerler sübjektif olarak görsel değerlendirme sonucu elde edildiği için, istatistiksel inceleme yapılamamıştır. 


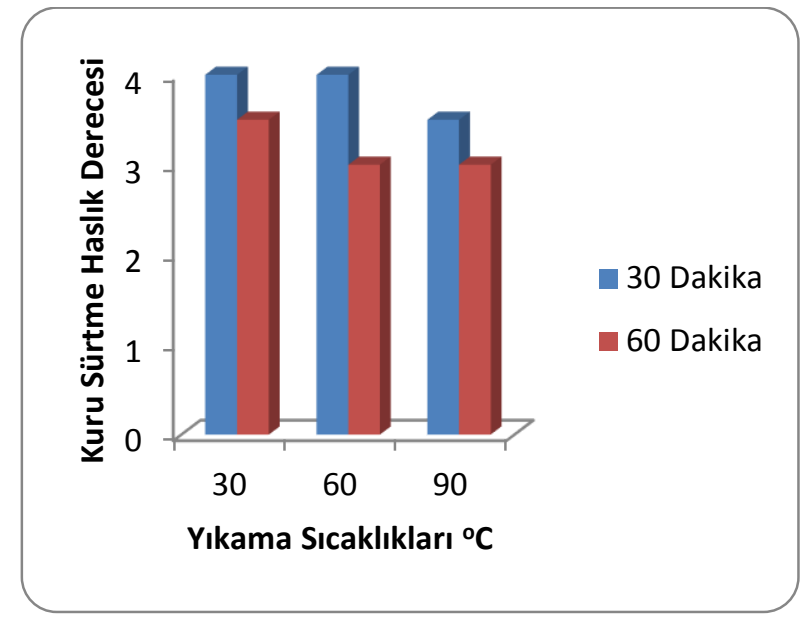

Şekil 1. Farklı yıkama sıcaklıklarında yıkama süreleri ile kuru sürtme haslık derecelerinin değişimi

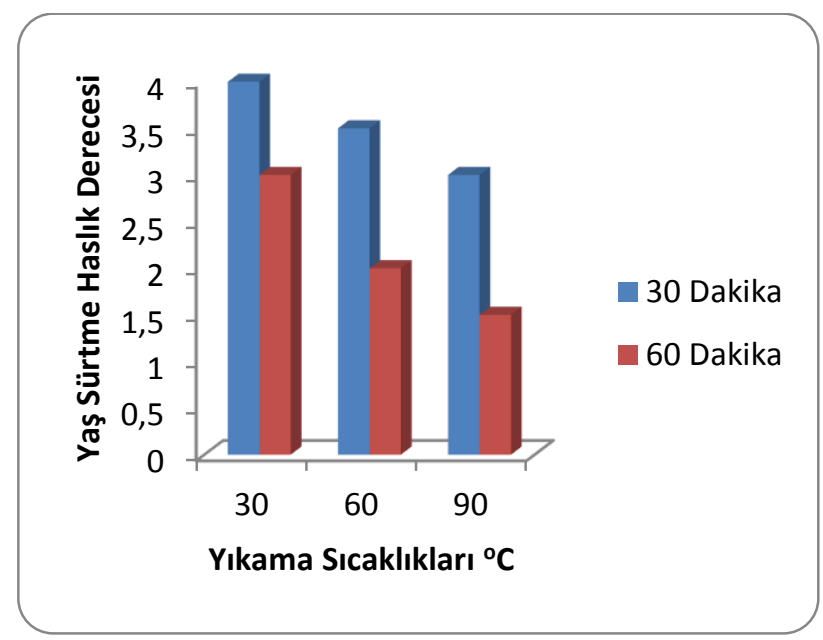

Şekil 2. Farklı yıkama sıcaklıklarında yıkama süreleri ile yaş sürtme haslık derecelerinin değişimi

Şekil 1 ve Şekil 2 birlikte incelendiğinde; 3 farklı yıkama sıcaklığı için de yıkama süresi arttıkça sürtme haslığının düştüğü görülmektedir. Bu düşüş yaş sürtme haslıklarında daha belirgindir. Yüzde olarak en fazla düşüş ise $90^{\circ} \mathrm{C}$ 'de yapılan yıkama sonrası ölçülen yaş sürtme haslığında görülmüştür. 30 dakika yıkama sonrası 3 olarak ölçülen yaş sürtme haslığı 60 dakikada yapılan yıkamada 1,5 değerine düşmüştür. Kumaşların kuru sürtme haslıkları genellikle yaş sürtme haslıklarından yüksektir.

\subsection{Yıkama Sıcaklığı ile Kumaş Sürtme Haslığının Değişimi}

1,2 ve 3 numaralı yıkamalar 30 dakikada ve sırasıyla $20^{\circ} \mathrm{C}, 60^{\circ} \mathrm{C}$ ve $90^{\circ} \mathrm{C}$ sıcaklıklarda yapılmıştır. 4 , 5 ve 6 numaralı yıkamalar ise 90 dakikada ve yine sırasıyla $20^{\circ} \mathrm{C}, 60^{\circ} \mathrm{C}$ ve $90^{\circ} \mathrm{C}$ sıcaklılarda yapılmıştır. 2 farklı süredeki yıkamalar için yıkama sıcaklığı ile sürtme haslığı arasındaki ilişkiler Şekil 3 ve Şekil 4'de görülmektedir.

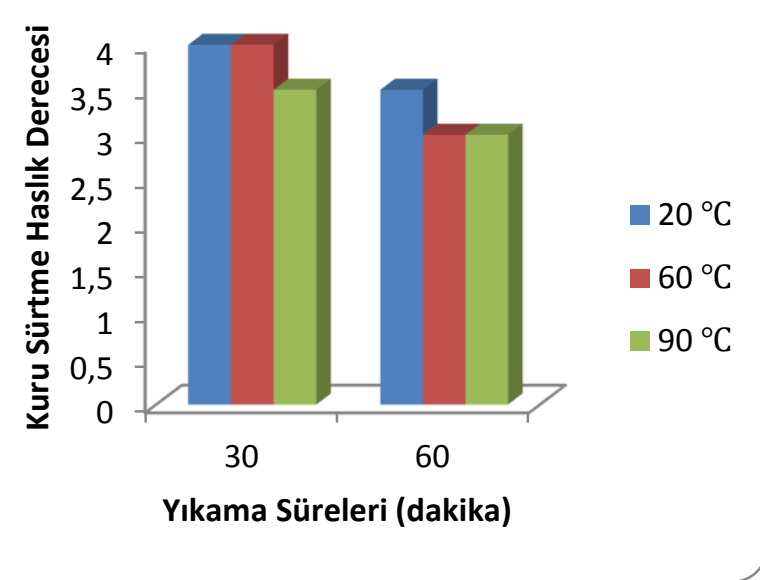

Şekil 3. Farklı yıkama sürelerinde yıkama sıcaklıkları ile kuru sürtme haslık derecelerinin değişimi

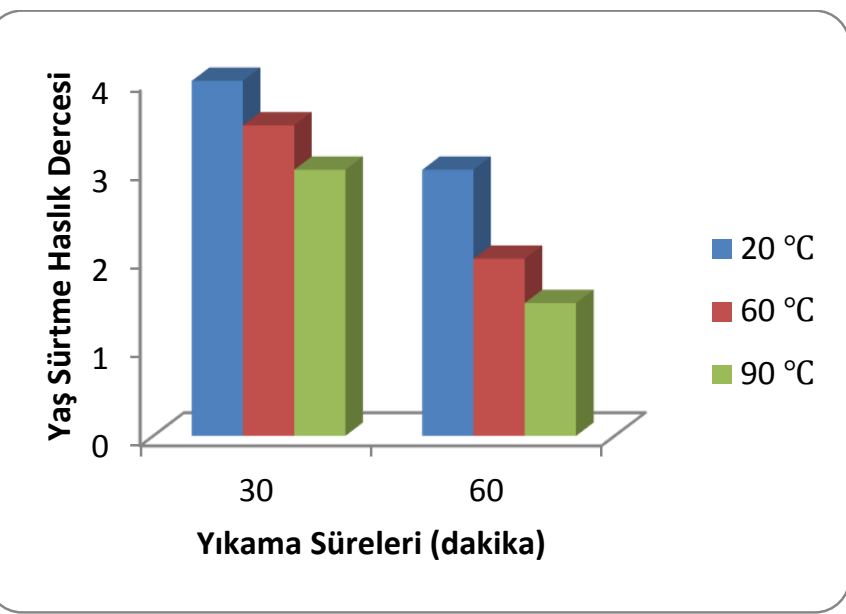

Şekil 4. Farklı yıkama sürelerinde yıkama sıcaklıkları ile yaş sürtme haslık derecelerinin değişimi

Şekil 3 ve Şekil 4 birlikte incelendiğinde; 2 farklı yıkama süresi için de yıkama sıcaklığı arttıkça sürtme haslığının düştüğü görülmektedir. Bu düşüş yaş sürtme haslıklarında daha belirgindir. Yüzde olarak en fazla düşüş ise 60 dakikada yapılan yıkama sonrası ölçülen yaş sürtme haslığında görülmüştür. $20^{\circ} \mathrm{C}$ 'de 3 olarak ölçülen yaş sürtme haslığ $160^{\circ} \mathrm{C}$ 'de $2^{\prime}$ ye $90^{\circ} \mathrm{C}$ ise 1,5'a düşmüştür. Kumaşların kuru sürtme haslıkları genellikle yaş sürtme haslıklarından yüksektir.

\subsection{Yıkama Tekrarı ile Kumaş Sürtme Haslığının Değişimi}

Tablo 4'de verilen 6 yıkama için yıkama tekrar sayısı ile sürtme haslığının arasındaki ilişkiler Şekil 5 ve Şekil 6'da verilmiştir. 


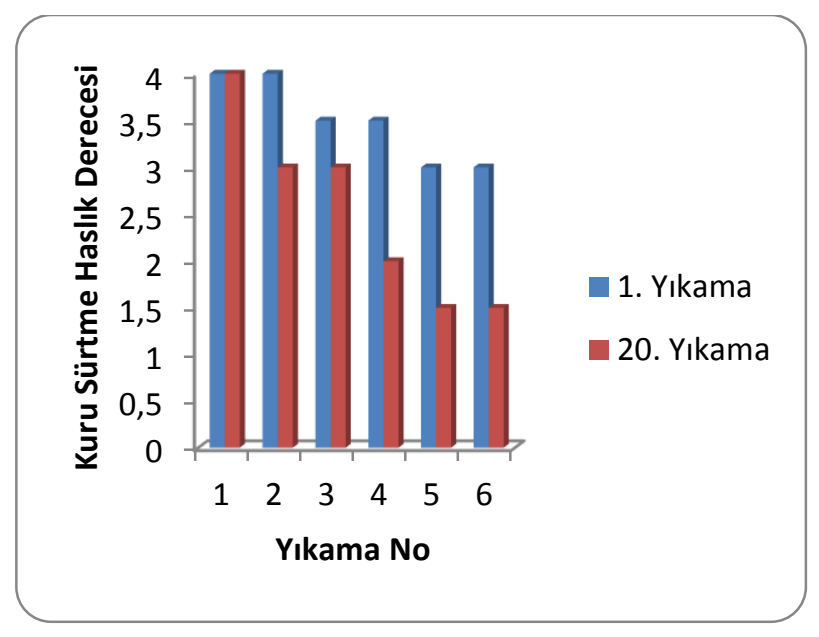

Şekil 5. Yıkama tekrarı ile kuru sürtme haslık derecelerinin değişimi

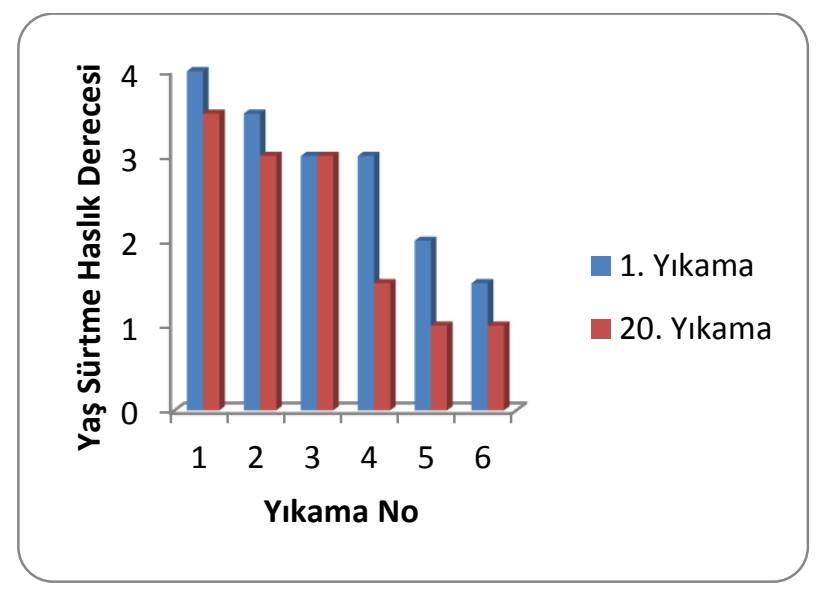

Şekil 6. Yıkama tekrarı ile yaş sürtme haslık derecelerinin değişimi

Şekil 5 ve Şekil 6 birlikte incelendiğinde; 6 farklı yıkama için de yıkama tekrarı artıkça sürtme haslığının düştüğü görülmektedir. Kuru sürtme haslığında toplam 6 birimlik düşüş yaşanırken yaş sürtme haslığında 4 birimlik bir düşüş görülmüştür. Yüzde olarak en fazla düşüş ise 5 . ve 6 . Yıkamalarda kuru sürtme haslığında 4. yıkama sonrası da yaş sürtme haslığında $\% 50$ olarak görülmüştür. Yine kumaşların kuru sürtme haslıkları genellikle yaş sürtme haslıklarından yüksektir.

\section{TARTIŞMA VE SONUÇ}

$\mathrm{Bu}$ çalışmada pamuklu bezayağı kumaşlara ev tipi yıkama makinesiyle 2 farklı süre ve 3 farklı sıcaklıkta yıkama işlemi uygulanmıştır. Ayrıca 6 farklı yıkama 20 kez tekrarlanarak yıkama süresi, yıkama sıcaklığı ve yıkama tekrarının kumaşların sürtme haslığına etkileri incelenmiştir. Elde edilen sonuçlara göre şu yorumlar yapılabilir.

- Genel olarak; yıkama süresi, yıkama sıcaklığı ve yıkama tekrarı arttıkça yaş ve kuru sürtme haslıkları düşmektedir.

- Kumaşların yaş sürtme haslıkları kuru sürtme haslıklarından daha düşüktür.

- Yıkama süresinin artmasıyla yaş sürtme haslıklarındaki düşüş daha belirgindir. Yaş haslıklar, elyafla kimyasal bağ yapmamış sadece elyafa tutunmuş boyarmaddelerden etkilendiği için yıkama süresinin artması bu boyarmaddeleri kumaştan uzaklaştırmış ve dolayısıyla haslıktaki düşüş daha belirgin olarak bulunmuştur.

- Yıkama sıcaklığını artmasıyla yaş sürtme haslıklarında daha belirgin düşüşler görülmüştür.

- Yıkama tekrarındaki artışlar kuru sürtme haslığında daha belirgin bir düşüşe sebep olmuştur.

Kumaşlar ve tekstil mamulleri kullanımları süresinde defalarca kez yıkanırlar. Yıkama ve kurutma işlemleri maliyeti yüksek olan işlemdir. Maliyeti daha da artıran diğer bir husus yıkama süresi ve yıkama sıcaklığının artırılmasıdır. Ayrıca süre ve sıcaklığın gereğinden yüksek olması tekstil ürünleri üzerinde bazı olumsuzluklara da sebep olmaktadır. $\mathrm{Bu}$ olumsuzluklardan bazıları; kumaşın boyut stabilitesini kaybetmesi, kumaşın deforme olması yani şekil bozukluğu ve sürtme haslığındaki düşmelerdir. Ayrıca yıkama işleminde su tüketimi oldukça yüksek ve atık sular sebebiyle de çevreyle ilişkili bir işlemdir. Bu sebeple yıkama faktörleri üzerinde dikkatlice durulması oldukça önemlidir.

Yapılan çalışma reaktif boyarmadde ile lacivert renkte boyanmış pamuklu bezayağı kumaşlar için geçerlidir. Genelleme yapılabilmesi için araştırmacılara aşağıdaki öneriler sunulabilir.

1. Farklı doku türleri ile üretilen kumaşlarda çalışılabilir.

2. Pamuk haricinde diğer liflerle üretilen kumaşlarda çalışılabilir.

3. Dokuma kumaşlar için farklı sıklık ve gramajlardaki kumaşlar üzerinde çalışılabilir.

4. Farklı boyarmaddeler, farklı renkler, farklı boyama yöntemleri ve farklı art işlemlerle çalışılabilir.

Yıkama süresi ve yıkama sıcaklığı ile birlikte y1kama maddesi konsantrasyonun da sistematik olarak değiştirilerek çalışılabilir. 


\section{KAYNAKLAR}

[1]. Yakartepe M. ve Yakartepe Z., 1995, Tekstil Terbiye Teknolojisi, Cilt 4, İstanbul

[2]. Çoban S., Terbiye ve Haslıklar Açısından Konfeksiyon Malzeme Muayeneleri, Ege Üniversitesi Tekstil ve Konfeksiyon Araştırma Uygulama Merkezi Yayını, Bornova İMIR, $126 \mathrm{~S}$.

[3]. Balcı O. Ve Oğulata R.T., Boyama Sonrası Poliester/Vizkon/Elastan Karıșımlı Dokuma Kumaşlarda Haslık İyileştirme Çalışmaları, Tekstil ve Mühendis, Sayı 61, 21-32.

[4]. Demirhan F., Meriç B., 2004. Örme Kumaş ve Giysilerde Y1kama ve Kurutma Sonrası Boyut Değişimlerinin İncelenmesi, Pamukkale Üniversitesi Mühendislik Bilimleri Dergisi, 11(3), $381-390$.

[5]. Erdem İşmal Ö., 2008. The Effect of Causticizing, Washing and Drying Processes on Shrinkage and Crease Resistance Properties of Viscose Fabric, Tekstil ve Konfeksiyon, Y11: 18(3), 221- 228.

[6]. Lau L., Fan J., Siu T. and Siu L.Y.C., 2002. Effects of Repeated on the Performance of Garments with Wrinkle - Free Treatment, Textile Research Journal, 72(10), 931-937.

[7]. Quaynor, L., Takahashi, M., Nakajima, M., 2000. Effects of Laundering on the Surface Properties and Dimensional Stability of Plain Knitted Fabrics, Textile Research Journal, 70(1), 28-35.

[8]. Önal, L. ve Candan, C., 2003. Contribution of Fabric Characteristics and Laundering to Shrinkage of Weft Knitted Fabrics, Textile Research Journal, 73(3), 187-191.

[9]. Yurdakul A., Öktem T.,Kumbasar P., Atav R., Korkmaz A, ve Arabac1 A., 2003, Boyama İşleminden Sonra Kullanılan Tekstil Kimyasallarının ve Diğer Terbiye İşlemlerinin Haslık Özellikleri Üzerine Etkileri, Tübitak Tekstil Araştırma Merkezi, Proje No: TAM 2002 - 02, İzmir.

[10]. Koç E. ve Ayyıldız Ç. Denim Kumaşlarda Performans Analizi II - Elastikiyet (Esneme) Sürtünme Haslığı ve Diğer Parametrelerin Belirlenmesi, Ç.Ü Müh. Mim. Fak. Dergisi, Cilt 19 Say1 2, 83-95.

[11]. Balcı O., Oğulata R.T., 2006, Boyama Sonrası Poliester/Viskon/Elastan Karışımlı Dokuma Kumaşlarda Haslık İyileştirme Çalışmaları, Tekstil ve Mühendis, Sayı 61,21-32.
[12]. Içoğlu H.İ. 2006. Pamuklu Dokunmuş Kumaşların Reaktif Boyarmaddelerle Boyanması ve Uygulama Yöntemlerinin İncelenmesi. Yüksek Lisans Tezi. Çukurova Üniversitesi Fen Bilimleri Enstitüsü Tekstil Mühendisliği Anabilim Dalı. 205 s.

[13]. Demir L., Mutlu Ö., 2006, Tekstil Terbiyesinde Uygulanan Art İşlemlerin Kuru Sürtme Haslığ 1 Üzerindeki Etkisinin İstatistiksel Deney Tasarım Yöntemi İle Belirlenmesi, Tekstil ve Mühendis, Say1 57, 39-49.

[14]. Tamtürk H.F. 2007. Pamuklu Dokuma Kumaşlara Uygulanan Seçilmiş Ön Terbiye İşlemlerinin Kumaş Performansına Etkisi. Yüksek Lisans Tezi, Çukurova Üniversitesi Fen Bilimleri Enstitüsü Tekstil Mühendisliği Anabilim Dalı. 149s.

[15]. Çetinaslan K.,Mezarcıgöz S., Çetiner S., 2013, Yıkama İşleminin Denim Kumaşların Kopma ve Yırtılma Mukavemetine Etkisi, KSU Mühendislik Bilimleri Dergisi, 16(1), 38-42. 